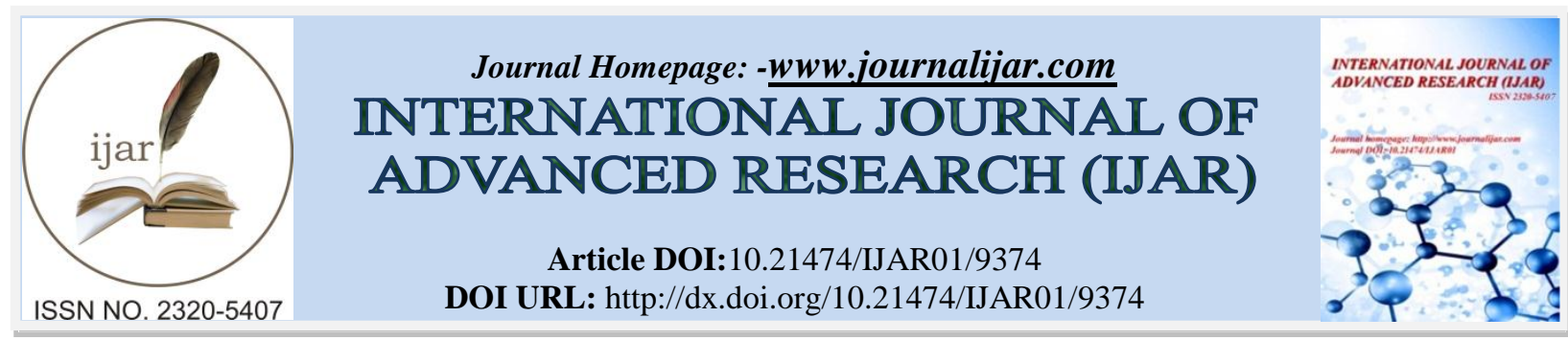

RESEARCH ARTICLE

\title{
EFFECTIVENESS OF VIDEO ASSISTED TEACHING MODULE ON KNOWLEDGE REGARDING FIRST AID FOR SELECTED HOME ACCIDENTS AMONG MOTHERS OF UNDER FIVE CHILDREN IN SELECTED AGANWADIS OF SHIVRAJPUR, KANPUR.
}

\author{
Josy Jose ${ }^{1}$, Minu S.R ${ }^{2}$ and Muhasin Muhammad ${ }^{3}$. \\ 1. Principal, Meerut Nursing College, Mulayam Singh Yadav Medical college campus, Meerut, Uttar Pradesh, \\ India. \\ 2. Assistant professor, Faculty of Nursing, Rama University, Mandhana, Kanpur, Uttar Pradesh. \\ 3. Assistant professor, SCPM college of Nursing, Gonda, Lucknow.
}

\section{Manuscript Info}

Manuscript History

Received: 10 May 2019

Final Accepted: 12 June 2019

Published: July 2019

Key words:-

Anganwadi, Video Assisted Teaching Module , First aid ,Mothers of under five children .

\begin{abstract}
Safety and security don't just happen they are the result of collective consensus and Public investment. A study aimed to assess the effectiveness of video assisted teaching module on knowledge regarding first aid for selected home accidents among mothers of under five children in selected aganwadis of Shivrajpur at Kanpur. An pre experimental one group pre test post test design was used for this study. A non probability convenient sampling technique was used. Sample size was 50 . The validity and reliability of tool was established. Closed ended questionnaire was used to collect the data. Data was analyzed by using descriptive and inferential statistics. Finding of the study revealed that highest percentage (36\%) of mothers of under five children belongs to the group of non formal education. The overall mean score in pre test was (14.92+-3.9) which is $49.73 \%$ of total score reveals that mothers of under five children had poor knowledge regarding first aid for selected home accidents. Whereas it was 20.5+- 3.9 (68.3\%) in post test, revealing $18.57 \%$ enhancement of knowledge score. Highly significant $(\mathrm{p}<0.05)$ difference was found between pre and post test knowledge score, Association between the pre test knowledge score with their selected demographic variables $(\mathrm{p}<0.05)$ was significant.
\end{abstract}

Copy Right, IJAR, 2019,. All rights reserved.

\section{Introduction:-}

Today's children are tomorrow's citizen; child hood is very special and vulnerable Period of life. A bright future for an individual for a family for a society, for a country lies in providing a safe environment for children to grow nature. Every parent think that they are good Parents and take great care in protecting children from any harm or dangers yet there is one Place where the child is more a risk than anywhere else, and that is their own home. No matter how careful parents are, there will be time when child is unsupervised. It only takes a split Second for a child to swallow something and choke ${ }^{[1]}$

Accidents are the leading cause of death and disability of children over the age of one in many industrialized countries. A child's environment plays a critical role, both in the occurrence and the severity of an injury. Most

Corresponding Author:-Josy Jose.

Address:-Principal, Meerut Nursing College, Mulayam Singh Yadav Medical college campus, Meerut, Uttar Pradesh, India. 
injuries take place in or near child's home where unsafe play areas and play things may often be found as well as access to chemicals medicines, poisons and other dangers. Age, sex and economic factors are important determinants of accident incidence and severity, not only are children particularly prone to accidents, but also the type of accident depend on age. Under five children tend to be more at risk for poisoning, Drowning and burns, suffocation and falls. ${ }^{[2]}$

In developing countries like India knowledge about domestic accidents less. Domestic Accidents is an important public health problem and the problem is more grave in rural India. Domestic accidents are one of the five leading cause of death in industrialized and developing. People from lower socio economic status, with underlying medical conditions, living poor housing conditions and lack of proper safety measures are at higher risk of domestic Accidents. Main domestic accidents commonly occur in children are poisoning, burns, falls and drowning. [3]

Poisoning refers to an injury resulting from exposure to exogenous substances that causes cellular injury or death. Poisons can be inhaled, ingested, injected or absorbed.

According to WHO and the United Nations Children's fund (UNICEF), poisoning in childhood is common because children are curious and explore their world with all their senses, including taste. Most of the time they are at home, and the home and its environment can be an unsafe place in which poisonous substances are unintentionally ingested. Poisoning is a significant global health problem. The extent of the problem is different from one country to the other. ${ }^{[4]}$

Today's modern risk results from the unsafe use of dangerous chemicals. Unsafe chemicals in toys and household products may also harm children. There are different types of poisoning. All are accidental and some do not have an immediate effect on a child. Poisoning is more common among younger age group. Poisoning is more common among younger age group. Poisoning is more frequent in toddler boys than girls because boys are more active adventuresome than girls. ${ }^{[5]}$

Pediatric burn can have long term physical, psychological, economic and social implications for parents and their families with ongoing treatment, rehabilitation, and the need for regular interventions. Pediatric burns occur more frequently in developing countries, with their incidence being many times higher in low and moderate -income countries compared to high- income countries. Studies worldwide have demonstrated that the incidence of burn injuries is highest among children below four years of age, with responsible factors ranging from children's impulsiveness, lack of awareness, higher activity levels due to natural curiosity, and total dependency on care givers. [6]

The world health organization broadly defines a burn injury caused by heat (cold, objects, gases or flames), chemicals, electricity and lightening, friction or radiation, annually burns result in more than 7.1 million injuries, the loss of almost 18 million disability adjusted life years and more than 250,000 deaths worldwide. More than $90 \%$ of the burden of burn injury borne by low and middle income countries. ${ }^{[7]}$

Childhood falls and their complications is a leading cause of the global burden of disease. While falls don't rank in the top 15 cause of death for children under $15 y$ ears, they rank $13^{\text {th }}$ as a leading cause of disability adjusted life years. Globally non-fatal falls account for between $25-52 \%$ of all medically treated injuries among children. The magnitude of falls like other unintentional injuries varies according to the age, sex, region, income, group, cultural background and kind of injury. Children's psychological characteristics influence injury occurrence as injuries are the result of specific interactions between the behavior of children and the surrounding environment. ${ }^{[8]}$

Drowning is the third leading cause of unintentional injury deaths among all Populations .Drowning is one of the major causes of mortality in the South -East Asia Region. India, as a whole has an average drowning death rate of 6.6 per 100,000 populations per year. ${ }^{[9]}$

\section{Statement of the problem -}

A study to assess the effectiveness of video assisted teaching module on knowledge regarding first aid for selected home accidents among mothers of under five children in selected home accidents among mothers of under five children in selected anganwadis of Shivrajpur at Kanpur. 


\section{Objectives of the study:-}

1. To assess the pre test knowledge regarding first aid for selected home accident among mothers of under five children.

2. To assess the effectiveness of video assisted teaching module on knowledge regarding first aid for selected home accidents among mothers of under five children

3. To find out the association between the pre test knowledge score with their selected demographic variable.

\section{Hypothesis}

1. H1:- The mean post test knowledge score of subjects exposed to Assisted Teaching Module on first aid for selected home accidents will be more than pre test knowledge as measured by structured knowledge test at 0.05 level of significance.

2. H2:- There will be a significant association between knowledge score of subjects and selected demographic variables at 0.05 level of significance.

\section{Materials and methods:-}

\section{Research design:-}

A quantitative research approach was used to evaluate the knowledge regarding the of mothers of under five children regarding first aid for selected home accidents and to find out the association between the pretest knowledge score with their selected demographic variables. Pre experimental one group pre test and post test was used to collect data.

\section{Setting of the study}

The study was conducted in selected aganwadis of shivrajpur, Kanpur.

\section{Variables}

Independent variables

In this study VATM on first aid for selected home accidents among mothers of under five children is the independent variables.

\section{Dependent variables}

In these study dependant variables refers to knowledge of mothers of under five children regarding first aid for selected home accidents.

\section{Demographic variables}

Age, education, occupation, Income, Type of the family and source of information.

\section{Population}

The population of the study was Mothers of under five children in shivarjpur, Kanpur.

\section{Sample}

The sample of the study was 50 mothers of under five children who fulfilled the sampling criteria.

\section{Sampling technique.}

With the help of non- probability convenient sampling technique, 50 mothers of under five children were selected as sample for the study.

\section{Data collection and analysis}

1. Closed ended questionnaire was used to collect data after testing validity and reliability.

2. Data analysis was done by both descriptive and inferential statistics on the basis of objective and hypothesis of study.

\section{Development and description of tool used in this study.}

The tool to assess the knowledge of mothers of under five children regarding first aid for selected home accidents was developed by the investigator .Validity and reliability of tool was checked.The tool consists of two sections. The tool used for the study include:-

\section{Section A:}


Demographic data consisted of items seeking information about background data of mothers of under five children such as age, occupation, educational status, income, type of family and source of information regarding first aid for selected home accidents.

\section{Section B:-}

It contained 30 structured items on various aspects related to introduction of first aid, domestic accidents, poisoning, burns, falls and drowning. Each item had 4 options for which instructions were clearly written for mothers of under five children to choose the best option. The options included both correct and incorrect responses i.e. one correct response and three in correct responses. The score for the correct response was ' 1 ' and score for the incorrect response was ' 0 '.

The tool was prepared by the investigator under the guidance of expert from the field of nursing and medicine.

\section{Development of Video Assisted Teaching Module (VATM) on first aid for selected home accident}

The idea to produce the particular video on first aid for selected home accident was developed by the investigator by keeping the following points in mind.

1. Video assisted teaching is one of the accepted teaching strategies.

2. Feasible to demonstrate the first aid on selected home accidents.

3. Assuming that it will promote the interest of the mothers and ultimately helps in

4. Improving the knowledge of mothers of under five children.

\section{Design and production of the video teaching}

The design of the video was based on the lesson plan. Rough planning was made regarding the shots which have to be taken. Because of the meticulous planning that had taken place, it was possible to carry out all the main shooting for the video in 5 days in Hindi. Rough editing of the program was carried out by the technician, and shown to the guide and co-guide for expert opinion. The suggestions and recommendations were incorporated. The video was then edited into its final shape as per the investigator's ideas by the editor. Once the final master video had been produced, it was used by the investigator to educate the mothers of under five children after their pre test.

\section{Data collection procedure}

The main study was planned for a period of 4 weeks in the month of July $1^{\text {st }}$ to July 302017.

50 samples were collected through convenient sampling technique. After taking the consent from the concerned samples the data were collected from the samples.

\section{Phase I:-}

With prior informed consent, pretest was conducted through closed ended questionnaire.

\section{Phase II:-}

The investigator administered video assisted teaching module as intervention.

\section{Phase III:-}

After 15 days post test was conducted to the same group by Video Assisted Teaching Module.

\section{Result Of The Study}

Table 1:-Frequency and percentage distribution of mothers of under five children with their demographic variables.

\begin{tabular}{|l|l|l|l|}
\hline \multicolumn{2}{|c|}{ N $=\mathbf{5 0}$} \\
\hline \multirow{3}{*}{ Age in years } & $18-22$ years & Frequency & Percentage \\
\cline { 2 - 4 } & $23-27$ years & 14 & $28 \%$ \\
\cline { 2 - 4 } & $28-32$ years & 16 & $32 \%$ \\
\cline { 2 - 4 } & $>33$ years & 4 & $8 \%$ \\
\hline \multirow{2}{*}{ Education } & Non formal education & 16 & $32 \%$ \\
\cline { 2 - 4 } & Primary & 15 & $36 \%$ \\
\hline
\end{tabular}




\begin{tabular}{|c|c|c|c|}
\hline & Higher secondary & 14 & $24 \%$ \\
\hline & Graduate and above & 3 & $6 \%$ \\
\hline \multirow{4}{*}{ Occupation } & House wife & 41 & $82 \%$ \\
\hline & Labourer & 7 & $14 \%$ \\
\hline & Government job & 1 & $2 \%$ \\
\hline & Private job & 1 & $2 \%$ \\
\hline \multirow{4}{*}{ Income } & $<5,000$ & 13 & $26 \%$ \\
\hline & $5001-10000$ & 18 & $36 \%$ \\
\hline & $10001-15,000$ & 12 & $24 \%$ \\
\hline & $>15,000$ & 7 & $14 \%$ \\
\hline \multirow{4}{*}{ Type of family } & Nuclear family & 28 & $56 \%$ \\
\hline & Joint family & 22 & $44 \%$ \\
\hline & Extended family & 0 & $00 \%$ \\
\hline & Nuclear family & 28 & $56 \%$ \\
\hline \multirow[t]{4}{*}{ Source of information } & Mothers & 28 & $56 \%$ \\
\hline & Family members & 8 & $16 \%$ \\
\hline & Neighbours & 1 & $2 \%$ \\
\hline & News papers & 13 & $26 \%$ \\
\hline
\end{tabular}

Above mentioned table depicts that according to the age group classification highest percentage of mothers of under five children were belong to the group of 23-27 years and >33 years. According to the education the highest percentage of mothers were belong to the group of non-formal education. On the basis of occupation highest percentage of mothers of under five children were belongs the group of house wife. On the basis of income, highest percentage of mothers of under five children were belongs to the group of income 5001-10000. On the basis of type of family, the highest percentage of mothers of under five childrens were belongs to the nuclear family. On the basis of sources of information, highest percentage of mothers of under five children got the information from their mothers.

Table 2:-Distribution of mothers of under five children according to the pretest knowledge score regarding theselected home accidents

\begin{tabular}{|l|l|l|l|}
\hline Knowledge & \multirow{2}{*}{ Score } & \multicolumn{2}{|l|}{ Respondants of knowledge level } \\
\cline { 3 - 4 } & & Pre test No & Mean \% \\
\hline Poor & $1-10$ & 9 & $18 \%$ \\
\hline Average & $11-20$ & 37 & $74 \%$ \\
\hline Good & $21-30$ & 4 & $8 \%$ \\
\hline Total & & 50 & $100 \%$ \\
\hline
\end{tabular}

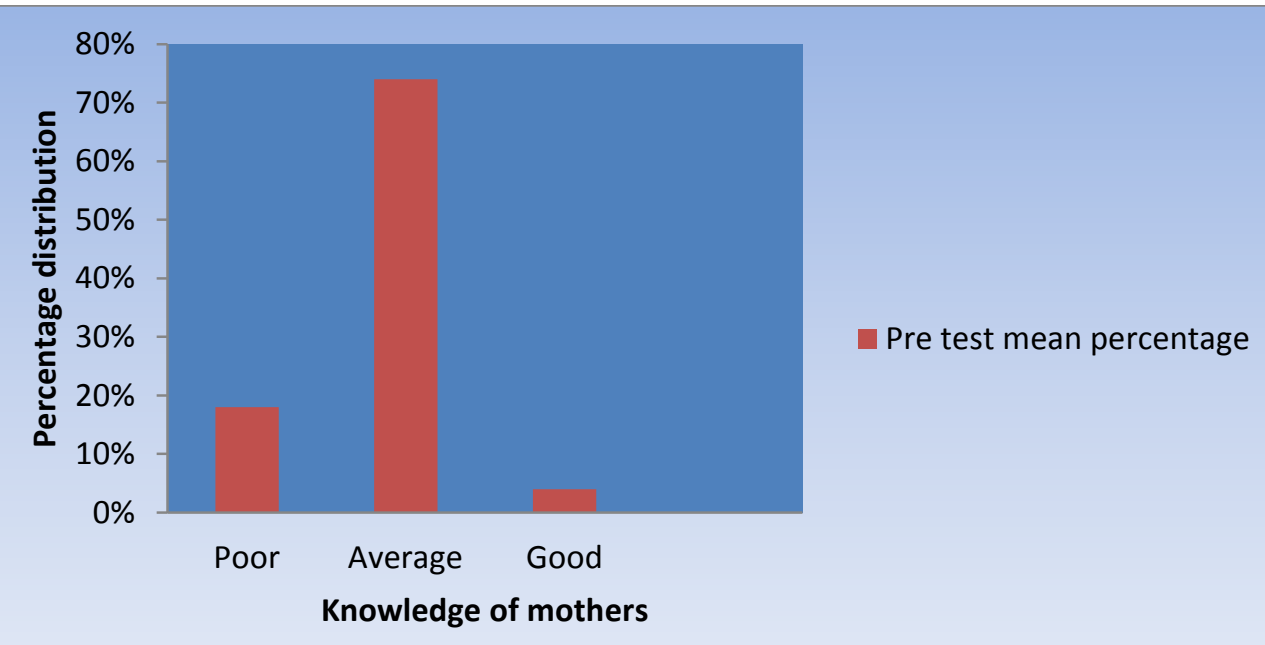

Fig 1:-Percentage distributions of mothers according to their pretest mean percentage score. 
The bar diagram depicts that around $74 \%$ of mothers of under five children had average knowledge, $18 \%$ mother had poor knowledge. Whereas $8 \%$ mother had good knowledge regarding first aid for the selected home accidents. It shows that average level of knowledge regarding first aid for selected home accidents among mothers of under five children was adequate.

Table 3:-Association of pretest knowledge score of mothers of under five children with their demographic variables.

\begin{tabular}{|c|c|c|c|c|c|c|}
\hline \multirow{3}{*}{$\begin{array}{l}\text { Demographic } \\
\text { Variables }\end{array}$} & \multirow[t]{3}{*}{ Category } & \multicolumn{4}{|c|}{ Respondents Knowledge } & \multirow{3}{*}{$\chi^{2}$ value } \\
\hline & & \multicolumn{2}{|c|}{ Below mean $(<15)$} & \multicolumn{2}{|c|}{ Above mean $(>15)$} & \\
\hline & & frequency & $\%$ & frequency & $\%$ & \\
\hline \multirow[t]{3}{*}{ Age } & $18-22$ & 8 & 16 & 6 & 12 & $7.546^{\mathrm{NS}}$ \\
\hline & $23-27$ & 11 & 22 & 5 & 10 & df -3 \\
\hline & $\begin{array}{l}28-32 \\
>33 \\
\end{array}$ & 0 & 00 & 4 & 8 & \\
\hline \multirow{4}{*}{$\begin{array}{l}\text { Educational } \\
\text { status }\end{array}$} & Non formal education & 7 & 14 & 11 & 22 & $7.82 *$ \\
\hline & Primary education & 8 & 16 & 7 & 14 & df -3 \\
\hline & Higher secondary education & 7 & 14 & 7 & 14 & \\
\hline & Graduate and above & 3 & 6 & 0 & 00 & \\
\hline \multirow[t]{4}{*}{ Occupation } & House wife & 20 & 40 & 21 & 42 & $7.82^{\mathrm{NS}}$ \\
\hline & Labourer & 3 & 6 & 4 & 8 & df -3 \\
\hline & Govt. Job & 1 & 2 & 0 & 00 & \\
\hline & Private Job & 1 & 2 & 0 & 00 & \\
\hline \multirow[t]{2}{*}{ Monthly income } & $<5000$ & 6 & 12 & 7 & 14 & $\begin{array}{l}8.72 * \\
\text { df }-3\end{array}$ \\
\hline & $\begin{array}{l}5001-10000 \\
10001-15,000 \\
>15,000\end{array}$ & $\begin{array}{c}12 \\
4 \\
3\end{array}$ & $\begin{array}{c}24 \\
8 \\
6\end{array}$ & $\begin{array}{l}6 \\
8 \\
4\end{array}$ & $\begin{array}{c}12 \\
16 \\
8\end{array}$ & \\
\hline \multirow{2}{*}{$\begin{array}{l}\text { Source of } \\
\text { information }\end{array}$} & $\begin{array}{l}\text { Nuclear } \\
\text { Joint family } \\
\text { Extended family } \\
\end{array}$ & $\begin{array}{c}12 \\
13 \\
0 \\
\end{array}$ & $\begin{array}{l}24 \\
26 \\
00 \\
\end{array}$ & $\begin{array}{c}16 \\
9 \\
0 \\
\end{array}$ & $\begin{array}{l}32 \\
18 \\
00 \\
\end{array}$ & df $-2^{1.3^{N S}}$ \\
\hline & $\begin{array}{l}\text { Mother } \\
\text { Family members } \\
\text { Neighbours } \\
\text { Newspaper } \\
\end{array}$ & $\begin{array}{c}5 \\
10 \\
1 \\
7 \\
\end{array}$ & $\begin{array}{c}10 \\
20 \\
2 \\
14 \\
\end{array}$ & $\begin{array}{c}23 \\
3 \\
00 \\
1 \\
\end{array}$ & $\begin{array}{c}46 \\
6 \\
00 \\
2 \\
\end{array}$ & $\begin{array}{l}20.52 * \\
\text { df }-3\end{array}$ \\
\hline
\end{tabular}

${ }^{\text {NS }}$ is not significant $*$ is significant

Above the table shows that association between overall pretest knowledge scores of mothers of under five children regarding first aid for selected home accidents and selected demographic variables of subjects such as age, educational status, occupation, monthly income, type of family and source of information.

When the chi square value was computed for educational status, income of the family and source of information, the obtained value was higher than the table value at 0.05 level. Hence there was statistically significant association with these selected baseline variables of mothers of under five children and their overall knowledge scores regarding first aid for selected home accidents. This shows that hypothesis 2 can be acceptedwith regard to these variables

But when the chi square values were computed for variables like of age, occupation and type of family, income, religion, the obtained value was less than the table value. So it was proven that there was no association between 
these variables with the overall knowledge scores mothers of under five children regarding first aid for selected home accidents.

\section{Discussion:-}

The mean post test knowledge score of subjects exposed to video assisted teaching module on first aid for selected home accidents will be more than pre test knowledge measured by structured knowledge test at 0.05 level of significance.

There is a significant association between knowledge score of subjects and selected demographic variables like educational statutes, monthly income and source of information of mothers at 0.05 levels of significance. Others between knowledge score of subjects and selected demographic variables like age, occupation, type of family are not significant at 0.05 levels.

Another study to assess the effectiveness of information booklet on knowledge of mothers regarding prevention of home accidents among children under five years urban community at Navi Mumbai, Maharashtra. The result of the study showed that the ' $t$ ' value was calculated for comparison of pre test and post test score of information booklet. There was significant difference in pre test and post test mean score, which showed that the information booklet was effective. The ' $t$ ' value was also calculated with independent ' $t$ ' test, paired ' $t$ ' test, chi square test and kolmogrov smrinov test. There was significant difference in pre test and post test mean score. Which showed that the information was effective? ${ }^{[10]}$

\section{Summary:-}

A pre experimental study was conducted on 50 mothers of under five children to assess the effectiveness of VATM regarding first aid for selected home accidents in anganwadis of Shivrajpur ,Kanpur. Data were collected from 10-72017 to 25-7 2017 through closed ended questionnaire. Collected data were analyzed by using descriptive and inferential statistics.

The findings are summarized as follows:

1. More or similar percentage was in the age group o between $23-27$ years (32\%) and >33years (32\%).

2. Almost all the mothers of under five children in the group of non formal education (36\%)

3. Most of the mothers were in the group of house wife (82\%)

4. Highest percentage (36\%) of mothers of under five children belonged to the income group of Rs.5001-10000.

5. Most of the mothers $(56 \%)$ belonged to the nuclear family.

6. Highest percentage of information (100\%) got from the mothers only.

7. The overall mean knowledge on mothers during pre test was $14.92+-3.9$ which is $49.73 \%$ of the total score reveals that the mothers of under five children have some knowledge regarding first aid for selected home accidents.

8. Total mean knowledge of mothers of under five children during post test was $20.5+-3.9$ which is $68.3 \%$ of the total score reveals that the mothers of under five children had good knowledge regarding first aid for selected home accidents.

9. Area wise post test mean score were above $60 \%$ of the total score in all areas reveals good knowledge.

10. Effectiveness of VATM was high for the mothers of under five children in the age group of 23-27 years.

11. Effectiveness of VATM was high for the mothers of under five children in the group of non formal education .

12. Effectiveness of VATM was high for the mothers of under five children in the group of house wife.

13. VATM was more effective in the income group of Rs 5001-10000.

14. Effectiveness of VATM was high in the group of nuclear family.

15. Effectiveness VATM was high in those who all are in the group of mothers. Highly significant difference was found between the pre and post test knowledge score.

16. There are three significant associations between knowledge score of mothers in pre test their education, income and source of information. Others do not have significant association between knowledge score of mothers in pre test their age, occupation, type of family regarding first aid for selected home accidents.

\section{Conclusion:-}

From the findings of the present study it can be concluded that VATM regarding First aid for selected home accident was effective to improve the mothers of under five children knowledge. 
Prior to the implementation of the VATM the mothers of under five children had mean pearcentage $49.73 \%$ of total score which reveals they have some knowledge, whereas after the implementation of VATM mothers of under five children had mean percentage $68.3 \%$ of total score which reveals good knowledge with the mean difference of $18.57 \%$.

\section{Implications}

The present study has several implications in Nursing service, Nursing education, Nursing research and Nursing administration.

\section{Nursing service}

Conduct awareness programs among mothers regarding first aid management of domestic accident and safety practices.

\section{Nursing education}

1. The findings of the present study can be a foundation for conducting the study on large section of population.

2. The studies can be baseline for the future studies to build up and motivate to conduct further studies.

\section{Nursing research}

1. The findings can be utilizes for conducting research on the effectiveness of VATM on various aspect of first aid for selected home accidents.

2. The findings can be used to plan further research in this area.

\section{Nursing administration}

1. The nurse administrator may allocate resources and provide motivation for further study in rural and urban areas.

2. Implement guidelines regarding Child Safety Policies in hospitals and communities

\section{Recommendations}

1. A comparative study can be conducted to identify the differences and similarities between rural and urban areas of mothers' knowledge level in first aid for selected home accidents.

2. An experimental study can be conducted with control group for comparison.

3. A similar study can be conducted in hospital settings.

4. The teaching and demonstration materials can be videotaped and can be shown to the mothers in outpatient department of hospital.

\section{Summary}

The chapter has dealt with summary of the findings, conclusion implication of the study in the nursing field and recommendation for the future.

\section{Bibliography:-}

1. Patel J, Pandya A, Ravindra HN. A study to assess the effectiveness of structure teaching programme on knowledge regarding prevention of childhood accidents among mothers of under five children at Piparia, Vadodara. IOSR Journal of Nursing and Health Science. (IOSR -JNHS). Sep. -Oct. 2014; 3(5):72-79.

2. Hema VH, Dilli BM. A descriptive study to assess the level of knowledge regarding first aid management of domestic accidents among mothers of under children and safety practices at home in rural village Chennai, International Journal of Nursing and Patient Safety and Care (TJPRC: IJNPSC). June 2016;1(1):31-38.

3. Sudhir, Krishna D, Nagaralu A, Channabasappa, Murali Dhar. Prevalence of domestic accidents in rural India: Across sectional study. Scholars Journal of Applied Medical Sciences (SJAMS).2014; 2 (2B): 657-659.

4. Ahmed A, Nazmi A, Aljamal, Ibrahim M, Salameh K, AIYafei K, et al. Poisoning emergency visits among children:a3-year retrospective study in Qatar. BMC Pediatrics. 2015;15 (104):1-7.

5. Namrata D, Uma K. A study to assess the effectiveness of structured teaching programme on knowledge regarding prevention of household injuries among the mothers of toddlers in selected village of Belgaum. Unique Journal of Medical and Dental Sciences. (UJMDS). 2014 [cited2014Sep.16];02(03):147150. Availablefrom:URL:http://www.ujcoonline.net.

6. Dhopte A, Tiwari VK, Patel P, Bamal R .Epidemiology of pediatric burns and future prevention strategies $-\mathrm{a}$ study of 475 patients from a high volume burn center in North India. Burns and Trauma. 2017; 5(1): 1-8. 
7. Rybarczyk MM, Schafer MJ,Elm MC, Sarvepalli S,Vaswani AP, Balhara SK, et.al. A systematic review of burn injuries in low-and middle-income countries: Epidemiology in the WHO -defined African region. African Journal of Emergency Medicine (AFJEM). August (2017); 30-37. Available from: URL:http://www.sciencedirect.com.

8. Chowdhury MS, Savanstorm L, Horte GL, Chowdhury AR, Rahman F. Children's perceptions about falls and their prevention: a qualitative study from a rural setting in Bangladesh. BMC Public Health. 2013; 13(1022):16.Available from:URL:http://www.biomedcentral.com.

9. World Health Organization.Drowning prevention in the south- East Asia Region- 2014. Regional Office for South -East Asia. Drowning prevention in the South-East Asia Region. 2014; 1-11

10. Salvi RJ. A study to assess the effectiveness of information booklet on knowledge of mothers regarding prevention of home accidents among children under five years in selected areas of urban community. International Journal of Nursing Research (IJNR). 